\title{
Neuregulin-1 impacting bone marrow mesenchymal stem cell migration is conducive to functional recovery following spinal cord injury
}

\author{
XI-MENG YIN, YI CHEN and GUAN-JUN TU \\ Department of Orthopedics, The First Affiliated Hospital of China Medical University, \\ Shenyang, Liaoning 110001, P.R. China
}

Received February 23, 2018; Accepted October 15, 2018

DOI: $10.3892 / \mathrm{mmr} .2019 .10217$

\begin{abstract}
The present study was designed to investigate the effect of neuregulin-1 (NRG1) on the migration of rat bone marrow mesenchymal stem cells (BMSCs) and evaluate the role of NRG1 in the functional recovery following spinal cord injury (SCI). Firstly, the effect of NRG1 on the mRNA expression of Snail in the BMSCs was detected by reverse transcription-quantitative polymerase chain reaction (RT-qPCR) analysis; secondly, the BMSCs were transfected with a Snail-overexpression plasmid (pBabe-puro-Snail) and the expression levels of Snail and matrix metalloptoreinase-2 (MMP-2) were detected by RT-qPCR and western blot analyses; thirdly, the cell proliferation and migration of BMSCs modified with pBabe-puro-Snail were detected by methyl thiazolyl tetrazolium and migration assays, respectively; finally, functional recovery of SCI was assessed using the Basso, Beattie, and Bresnahan rating scales. The results showed that NRG1 concentration-dependently promoted the expression of Snail with a peak at $40 \mathrm{ng} / \mathrm{ml}$ and $48 \mathrm{~h}$; NRG1 enhanced the promoting effect of Snail on the expression of MMP-2; the overexpression of Snail did not enhance the cell growth of the BMSCs. The NRG1-modified BMSCs promoted the functional recovery of SCI. These results suggested that NRG1 significantly promoted the expression of MMP-2 by upregulating the expression of Snail, and enhanced cell migration of the BMSCs conducive to the functional recovery of SCI.
\end{abstract}

\section{Introduction}

Spinal cord injury (SCI) can lead to permanent neurological deficits, including motor and sensory impairments, with high

Correspondence to: Dr Guan-Jun Tu, Department of Orthopedics, The First Affiliated Hospital of China Medical University, 155 Nanjing North Street, Heping, Shenyang, Liaoning 110001, P.R. China

E-mail: j1981790474@126.com

Key words: neuregulin-1, bone marrow mesenchymal stem cell, snail, matrix metalloproteinase-2, spinal cord injury physical disability and mortality rates. It can lead to serious damage to patients' physical and mental health, and cause severe social problems and economic burden (1). Although there are currently no effective therapies for the treatment of SCI, various types of stem cells, including embryonic, fetal and adult stem cells, have been widely used in cellular transplantation therapies for SCI, attracting increasing attention due to their satisfactory pre-clinical therapeutic effects (2). Among them, bone marrow mesenchymal stem cells (BMSCs) have emerged as one of the most promising types of stem cells due to their favorable ethical and safety profiles (3). Various studies have suggested that BMSCs transplanted directly into the lesion can promote axonal regeneration and contribute to motor and sensory improvement following SCI (4). The underlying mechanisms may include the differentiation of BMSCs toward neuronal cells for improving structural and functional repair of SCI and the secretion of various neurotrophic cytokines stimulating nerve growth, including brain-derived neurotrophic factor, nerve growth factor, vascular endothelial growth factor, fibroblast growth factor, hepatocyte growth factor, insulin-like growth factor and stem cell-derived factor $(5,6)$.

Neuregulins (NRGs) comprise a large family of widely expressed epidermal growth factor (EGF)-like proteins which are essential in neural development and brain activity homeostasis (7). Four NRG genes (NRG1-4) and 30 NRG isoforms have been reported previously (8). The NRG1 gene isoforms are composed of three types and the NRG1 type I isoform, also known as heregulin (HRG, $44 \mathrm{kDa}$ ) containing an Ig-like region and a glycosylation-rich segment, is predominantly expressed in the nervous system due to its acetylcholine receptor-inducing activity (9). HRG can promote the survival of neurons, glial cells $(10,11)$, epithelial cells (12), cardiomyocytes $(13,14)$ and other cell types (15) binding with ErbB tyrosine kinase transmembrane receptors, including ErbB1/EGFR (16), ErbB2/neu (17), ErbB3 (18) and ErbB4 (19). The NRG/ErbB3/4 signaling pathway is important in the regulation of numerous neurodevelopmental and activity-dependent processes, including cellular growth, proliferation, differentiation, migration and apoptosis (20).

Originally, the epithelial-mesenchymal transition (EMT) was identified as a morphological conversion occurring at 
specific stage of embryonic development and in the transitional stage between the early stage and progressive stage of tumors (21). The Snail signaling pathway may be involved in the migration of stem cells due to its well-established role in the EMT process (22). Although the role of Snail in tumor-related invasion and metastasis has been elucidated, there remains no clear understanding on its effects on the function of BMSCs.

Therefore, the present study aimed to clarify the underlying mechanism of NRG1 in the migration of BMSCs contributing to the functional recovery of SCI. Firstly, the association between NRG1 and Snail was investigated. Subsequently, an animal model of SCI was established using Allen's method and BMSCs modified with a Snail-overexpression plasmid vector were transplanted into the lesion of the spinal cord. The expression levels of NRG1, Snail and matrix metalloproteinase-2 (MMP-2) were detected by western blot and reverse transcription-quantitative polymerase chain reaction (RT-qPCR) analyses. Furthermore, the functional recovery of the spinal cord was evaluated using the Basso, Beattie, and Bresnahan (BBB) rating scales.

\section{Materials and methods}

Cell cultures. The green fluorescent protein (GFP)-labeled rat BMSCs were purchased from Cyagen Biosciences, Inc. (Guangzhou, China) and $>95 \%$ BMSCs expressed GFP (Fig. 1). The surface markers of $\mathrm{CD}_{4} 4^{+}, \mathrm{CD} 90^{+}, \mathrm{CD} 11 \mathrm{~b}$, $\mathrm{CD}^{-} 4^{-}$and $\mathrm{CD}^{-} 5^{-}$were confirmed by the manufacturer. The BMSCs were cultivated in Dulbecco's modified Eagle's medium (DMEM)/F12 with 10\% fetal bovine serum (FBS), $100 \mathrm{U}$ penicillin and $100 \mathrm{mg} / \mathrm{ml}$ streptomycin (Gibco; Thermo Fisher Scientific, Inc.). The cells were maintained at $37^{\circ} \mathrm{C}$ in a humidified atmosphere containing $5 \% \mathrm{CO}_{2}$ and passaged routinely for experiments.

RT-qPCR analysis. Total RNA from the BMSCs was extracted using TRIzol (Takara Bio, Inc., Otsu, Japan) according to the manufacturer's protocol. The concentration was detected by measuring the UV-absorption at $260 \mathrm{~nm}$. The reaction mixture obtained following the manufacturer instruction, was incubated at $42^{\circ} \mathrm{C}$ for $45 \mathrm{~min}$ and $85^{\circ} \mathrm{C}$ for $10 \mathrm{~min}$. The primers were designed as follows: Snail, forward 5'-ATGCACATC CGAAGCCACACGC-3' and reverse 5'-GTAGGTTGGAGC GGTCGGCAAA-3'; MMP-2, forward 5'-TTTCCATTCCGC TTCCAGGGCACAT-3' and reverse 5'-TCGCACACCACA TCTTTCCGTCACT-3'; GAPDH, forward 5'-GTCTTCACC ACCATGGAGAAGGCTG-3' and reverse 5'-TGAGGTCCA CCACCCTGTTGCTGTA-3'. qPCR analysis was performed using a SYBR Premix Ex Taq II kit (Takara Bio, Inc., Otsu, Japan) with $20 \mu \mathrm{l}$ solution containing $10 \mu \mathrm{l}$ reaction mixture, $2 \mu \mathrm{l}$ of cDNA, and $300 \mathrm{nM}$ of gene-specific primers. The PCR samples were denatured at $95^{\circ} \mathrm{C}$ for $3 \mathrm{~min}$ and 40 cycles were performed at $95^{\circ} \mathrm{C}$ for $12 \mathrm{sec}$, and at $62^{\circ} \mathrm{C}$ for $40 \mathrm{sec}$. The efficiency of the reaction was measured with primers using serial dilutions of the cDNA (1:1, 1:5, 1:25, 1:125, 1:625 and 1:3,125). Each sample was tested in triplicate. The relative gene expression levels were analyzed using the Pfaffl method. The data are expressed as fold change relative to untreated controls after normalizing to $\beta$-actin (23).
Overexpression plasmid and transfection. The Snail overexpression plasmid (pBabe-puro-Snail), the mammalian expression vector with full length human Snail cDNA, and the negative comparing plasmid (pBabe-puro) were provided by Dr Bob Weinberg (Five Cambridge Centre, Cambridge, MA, USA) from Addgene, Inc. (Cambridge, MA, USA). The BMSCs were transfected with the Snail overexpression plasmid using Lipofectamine 2000 (Invitrogen; Thermo Fisher Scientific, Inc., Waltham, MA, USA) based on the manufacturer's protocol. Ampicillin-resistant clones were isolated as single colonies.

Methyl thiazolyl tetrazolium (MTT) assay. Each group ( $5 \times 10^{4}$ cells per well) of cells were incubated in 96-well plates containing $100 \mu \mathrm{l}$ DMEM (Gibco; Thermo Fisher Scientific, Inc.) in each well. The rates of cellular proliferation were measured following 24,48, 72, and $96 \mathrm{~h}$ of incubation. Subsequently, $20 \mu \mathrm{l}$ of MTT $(5 \mathrm{mg} / \mathrm{ml})$ was added into each well and incubated for $4 \mathrm{~h}$ at $37^{\circ} \mathrm{C}$. Following removal of the culture medium from each well, $150 \mu \mathrm{l}$ of DMSO was added to each well and the well-plate was detected using a spectrometer at $490 \mathrm{~nm}$.

Western blot analysis. RIPA lysis buffer was added into the cell suspension and reacted for $30 \mathrm{~min}$ at $4^{\circ} \mathrm{C}$. Subsequently, the samples were boiled for $10 \mathrm{~min}$ and centrifuged at $12,000 \mathrm{x} \mathrm{g}$ for $5 \mathrm{~min}$ at room temperature. The supernatants were collected and the quantity of protein loaded per well was adjusted. The protein sample $(20 \mathrm{mg})$ from each lysate was separated by using 10-12\% sodium dodecyl sulfate-polyacrylamide (SDS-PAGE) gel electrophoresis, transferred onto nitrocellulose membranes. The membranes were blocked using 5\% non-fat milk in PBS ( $\mathrm{pH}$ 7.2) for $2 \mathrm{~h}$ at room temperature and incubated with primary antibodies overnight at $4^{\circ} \mathrm{C}$, including anti-Snail (1:500; ab53519; Abcam, Cambridge, MA, USA), anti-MMP-2 (1:100; ab135562; Abcam) and GAPDH (1:400; ab8245; Abcam). The membranes were then washed with $1 \%$ TBS-Tween and incubated with secondary antibodies for $2 \mathrm{~h}$ at room temperature. An ECL chemiluminescent substrate kit was used to detect the reaction and images were analyzed using AlphaEase FC software version 3.0 (ProteinSimple, San Jose CA, USA). The western blot assays were conducted in at least three independent experiments.

Cell migration assay. The migration of stem cells was measured based on counting the number of cells that passed through a gelation-coated polycarbonate membrane with an $8-\mu \mathrm{m}$ pore size. The cells were suspended and seeded onto the Transwell membrane with the density of $1 \times 10^{3}$ cells/well. For chemotaxis experiments, 15\% FBS (Gibco; Thermo Fisher Scientific, Inc.) were placed into the wells of the lower chamber compartment. The cells were fixed with methanol at $-20^{\circ} \mathrm{C}$ for $30 \mathrm{~min}$ and stained with Giemsa at room temperature for $30 \mathrm{~min}$. The number of migratory cells was counted with an inverted microscope at x200 magnification in five fields.

SCI model. A total of 36 six-week-old female Sprague-Dawley (SD) rats were purchased from the Laboratory of Animal Technology of China Medical University (CMU; Shenyang, China). All rats were housed under specific pathogen-free conditions (22C, 12-h light/dark cycle and 50-55\% humidity) with free access to food pellets and tap water. The SD rats (body 

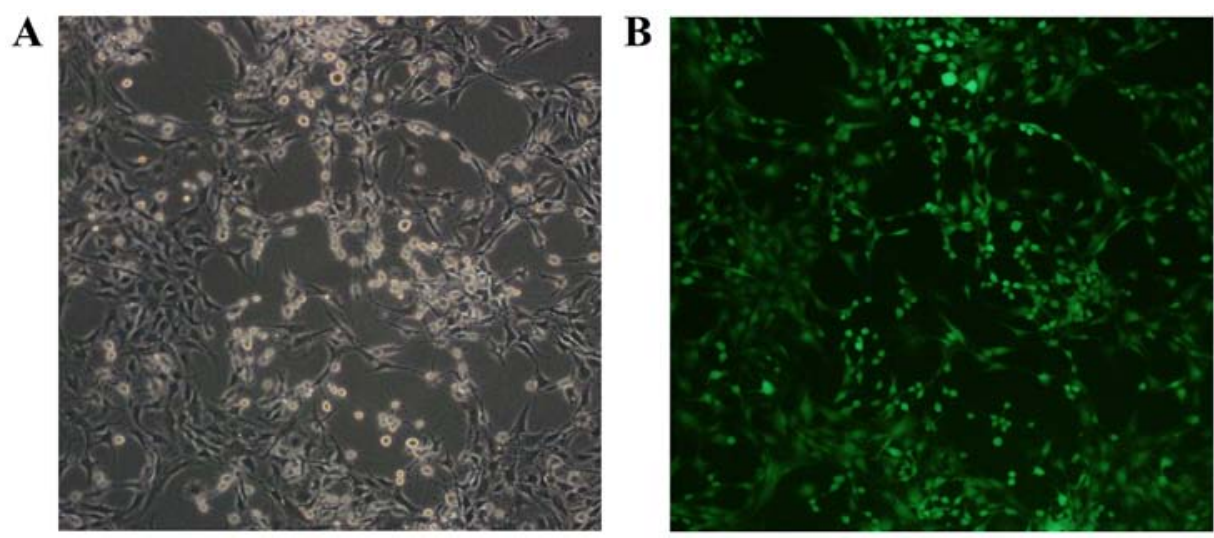

Figure 1. Green fluorescence protein-labeled rat bone marrow mesenchymal stem cells. (A) Cell morphology under an optical microscope (x100 magnification); (B) cell morphology under a fluorescent microscope (x100 magnification).

weight range, 200-240 g) were anesthetized by intraperitoneal injection of chloral hydrate $(300 \mathrm{mg} / \mathrm{kg})$ and received a laminectomy at the 10th thoracic vertebral body under a surgical microscope. The animals received $80 \mathrm{~g} / \mathrm{cm}$ blast injury using the Infinite Horizon Impactor (Laboratory Technology Center of CMU). A $1-\mu 1$ cell suspension of $1 \times 10^{5}$ cells was injected into the lesions of the spinal cord. Subsequently, 5-0 chromic gut sutures were used for suturing of the incision layer by layer and pressure was placed on the bladder for urination every day. Ampicillin was administered daily in order to avoiding infections during the entire study. All experiments were performed in accordance with the Chinese Community Guidelines (24).

$B B B$ scoring and specimen preparation. The functional recovery of the spinal cord was evaluated using the BBB rating scales (25); this was performed by two observers in a blinded-manner every week following cell transplantation. Subsequently, the rats were sacrificed with an overdose of sodium pentobarbital, followed by trans-cardiac perfusion with $4 \%$ paraformaldehyde fixing for $2 \mathrm{~h}$. The specimens, cut into segments $1 \mathrm{~cm}$ in length, were placed in $30 \%$ sucrose solution for $48 \mathrm{~h}$. These entire segments were cryosectioned longitudinally into $6-\mu \mathrm{m}$ serial sections and collected on slides. The numbers of GFP-labeled cells were counted under a fluorescence microscope.

Statistical analysis. Statistical analysis was performed using Statistical Product and Service Solutions software (SPSS 19.0; IBM Corp, Armonk, NY, USA). The results are presented as the mean \pm standard deviation. One-way analysis of variance was applied for the comparison of mean values of different groups and Tukey's test was used as post hoc test. $\mathrm{P}<0.05$ was considered to indicate a statistically significant difference.

\section{Results}

NRG1 significantly increases the $m R N A$ expression level of Snail in a concentration-dependent manner. The effects of different concentrations of NRG1 $(0-80 \mathrm{ng} / \mathrm{ml})$ on the mRNA expression level of Snail were detected by RT-qPCR analysis at 24, 48, and $72 \mathrm{~h}$. As shown in Fig. 2A, NRG1 significantly increased the mRNA expression of Snail in a concentration-dependent manner between 0 and $40 \mathrm{ng} / \mathrm{ml}$, with a peak at $40 \mathrm{ng} / \mathrm{ml}$. At the dose of $80 \mathrm{ng} / \mathrm{ml}$ NRG1, the expression level of Snail was significantly lower than that at the dose of $40 \mathrm{ng} / \mathrm{ml}$ NRG1. The mRNA expression level of Snail was significantly higher at $48 \mathrm{~h}$ than that at either 24 or $72 \mathrm{~h}$ post-NRG1 treatment $(\mathrm{P}<0.05)$. These results suggested that NRG1 at a dose of $40 \mathrm{ng} / \mathrm{ml}$ for $48 \mathrm{~h}$ led to the most effective increase on the expression of Snail in BMSC, which was the optimal condition used in the following experiments.

Effects of NRG1 on the mRNA and protein expression levels of Snail and MMP-2. A total of six groups were included in the study: Group A (BMSCs transfected with Snail overexpression plasmid plus NRG1; BMSC-Sna + NRG1), group B (BMSCs transfected with Snail negative expression plus NRG1; BMSC-NC + NRG1), group C (BMSCs plus NRG; BMSC + NRG1), group D (BMSCs transfected with Snail overexpression; BMSC-Sna), group E (BMSCs transfected with Snail negative expression; BMSC-NC) and group $\mathrm{F}$ (BMSCs). As shown in Fig. 2B, the expression levels of Snail mRNA in groups $A$ and $D$ were significantly higher than those in groups B, C, E and F due to transfection with the Snail overexpression plasmid $(\mathrm{P}<0.05)$. There were significant differences between group A and group D $(\mathrm{P}<0.05)$. Furthermore, the mRNA expression levels of MMP-2 in groups A and D were significantly higher than those in groups $\mathrm{B}, \mathrm{C}, \mathrm{E}$ and $\mathrm{F}$, which indicated that the overexpression of Snail stimulated the expression of MMP-2, and NRG1 further enhanced this positive effect of Snail ( $\mathrm{P}<0.05$; Fig. 2C). As shown in Fig. 3, no significant differences in cellular viability were observed between groups $\mathrm{D}, \mathrm{E}$ and $\mathrm{F}$ at different time points $(\mathrm{P}>0.05)$. This indicated that the cellular growth of BMSCs did not significantly alter due to transfection with the Snail overexpression plasmid. According to Fig. 4A-C, the results of the western blot analysis revealed that the expression level of Snail in group A was significantly higher than those of groups B, C, $\mathrm{E}$ and $\mathrm{F}(\mathrm{P}<0.05)$ and the expression level of Snail in group was significantly higher compared with those of groups $\mathrm{E}$ and $\mathrm{F}$ $(\mathrm{P}<0.05)$. No significant differences were observed between groups $\mathrm{A}$ and $\mathrm{D}(\mathrm{P}>0.05)$. In addition, the expression levels of MMP-2 in groups A and D were significantly higher than those of groups $\mathrm{B}, \mathrm{C}, \mathrm{E}$ and $\mathrm{F}(\mathrm{P}<0.05)$. 

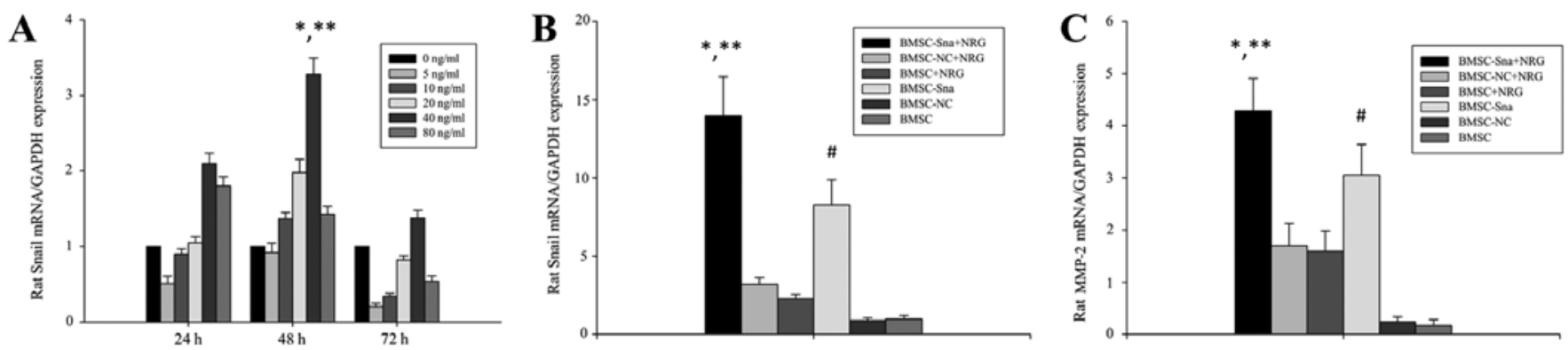

Figure 2. Effects of NRG1 on the expression levels of Snail and MMP-2. (A) NRG1 concentration-dependently increased the expression level of Snail. *P<0.05 48. vs. $24 \mathrm{~h}$; ${ }^{* *} \mathrm{P}<0.05$ 48, vs. $72 \mathrm{~h}$. Expression levels of (B) Snail and (C) MMP-2 in the different groups of BMSCs. ${ }^{*}<0.05$ BMSC-Sna + NRG group, vs. BMSC-NC + NRG, BMSC + NRG, BMSC-NC, and BMSC groups; * P<0.05 BMSC-Sna + NRG group, vs. BMSC-Sna group; "P<0.05 BSMC-Sna group, vs. BMSC-NC + NRG, BMSC + NRG, BMSC-NC, and BMSC groups. Data are presented as the mean \pm standard deviation and $\mathrm{P}<0.05$ was considered statistically significant. BMSC, bone marrow mesenchymal stem cells; Sna, Snail overexpression plasmid; NRG, neuregulin-1; NC, negative control; MMP-2, matrix metalloproteinase-2.

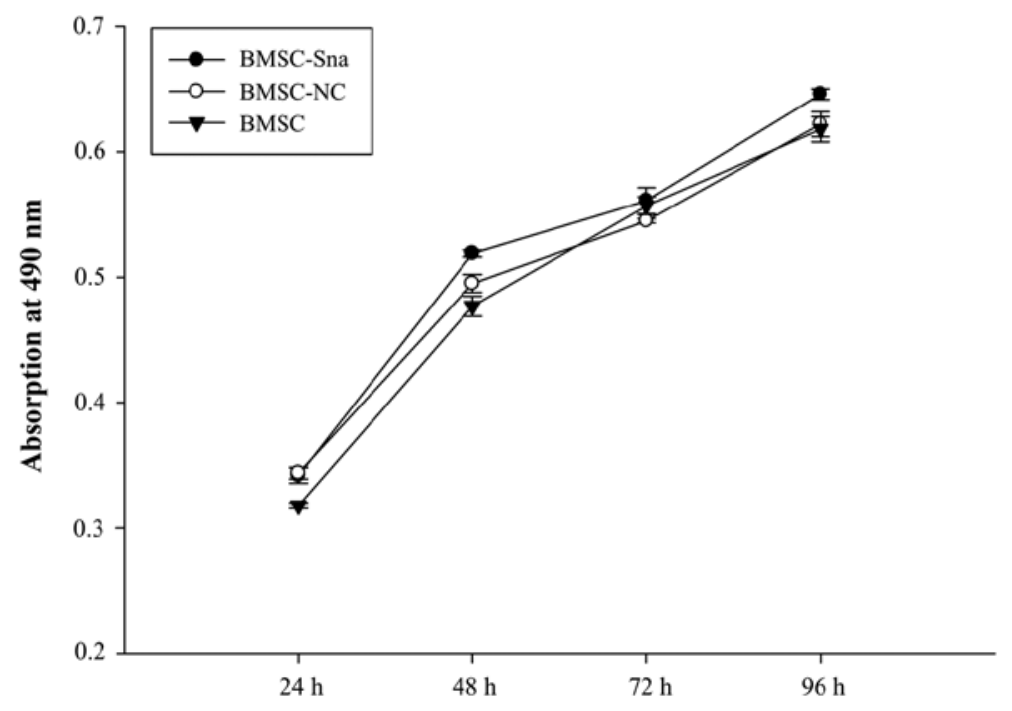

Figure 3. Cellular growth of BMSCs in different groups. Data are presented as the mean \pm standard deviation. BMSC, bone marrow mesenchymal stem cells; Sna, Snail overexpression plasmid; NC, negative control.

Cell migration of BMSCs in vitro. As shown in Fig. 5A and B, the numbers of cells crossing the membrane in groups $A$ and $D$ were significantly higher than those in groups $\mathrm{B}$ and $\mathrm{C}(\mathrm{P}<0.05)$. Additionally, there were significant differences between groups $\mathrm{A}$ and $\mathrm{D}$ in the numbers of cells that crossed the membrane $(\mathrm{P}<0.05)$. However, no cells appeared to cross the membrane in groups $\mathrm{E}$ and $\mathrm{F}$. This suggested that NRG1 enhanced the promoting effect of Snail on BMSC migration.

$B B B$ scores and assessment of functional recovery. Two experts were invited to perform the BBB rating scale in a blinded-manner at the end of each week between weeks 0 and 4 following cell transplantation. The BBB scores of group D were significantly higher than those of groups $\mathrm{B}, \mathrm{C}, \mathrm{E}$ and $\mathrm{F}$ between 1 and 4 weeks post-BMSC transplantation $(\mathrm{P}<0.05)$. The BBB score of group A was significantly higher than the scores of the other groups at different time points, including weeks 2, 3 and 4 ( $\mathrm{P}<0.05$; Fig. 6). In addition, the distribution area of BMSCs in group A was significantly larger than those of the other groups and the distribution area of BMSCs in group $\mathrm{D}$ was significantly larger than those of groups $\mathrm{E}$ and $\mathrm{F}$ (Fig. 7A-G).

\section{Discussion}

Currently, substantial efforts are required for fulfilling the clinical application of stem cell transplantation in the treatment of SCI $(26,27)$. In particular, the inefficient migration of BMSCs into the lesions in vivo is one of biggest problems in these studies. Several previous studies have suggested that stromal cell-derived factor-1 (28), monocyte chemoattractant protein-1 (29) and interleukin-8 can induce BMSC migration in vitro. However, there are no reports on whether NRG1 can induce BMSC migration into lesions of SCI and its underlying mechanisms.

The application of BMSCs as seed cells is effective and efficient for cell transplantation in the treatment of SCI due to lower immunogenicity and no adverse reactions (30). However, Serakinci et al (31) suggested that the existence of tumorigenicity was confirmed when BMSCs were transfected with the telomerase gene in vitro. In addition, Rubio et al (32) reported that transgenic BMSCs are safe and effective for 6-8 weeks in vitro, however, spontaneously emerging mutations were inevitable in the long-term. Therefore, temporary tumorigenesis BMSCs were introduced in the present study, 

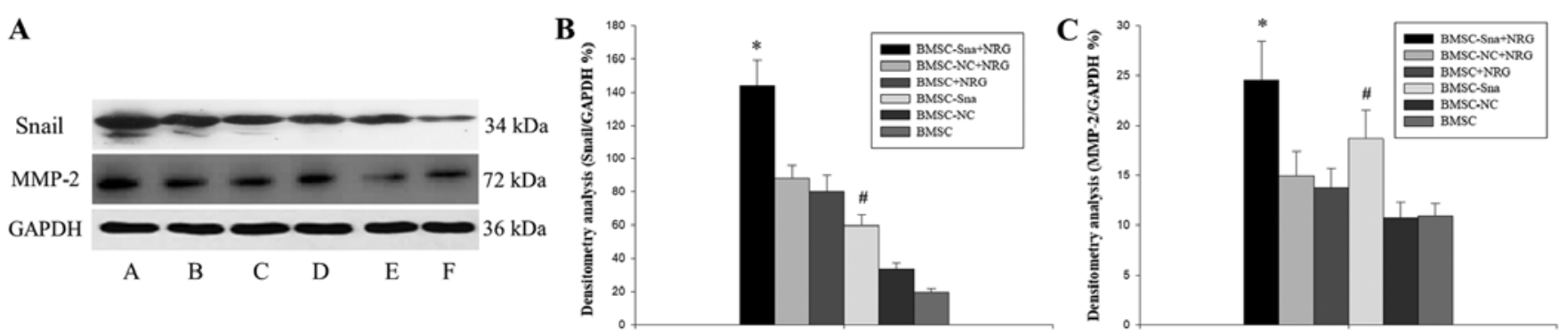

Figure 4. Western blot analysis results. (A) Expression of Snail and MMP-2 in the different groups of BMSCs: A, BMSC-Sna + NRG; B, BMSC-NC + NRG; C, BMSC + NRG; D, BMSC-Sna; E, BMSC-NC; F, BMSC. Densitometric analysis of (B) Snail and (C) MMP-2. Data are presented as the mean \pm standard deviation and $\mathrm{P}<0.05$ was considered statistically significant. ${ }^{*} \mathrm{P}<0.05$ BMSC-Sna + NRG group, vs. BMSC-NC + NRG, BMSC + NRG, BMSC-NC, and BMSC groups; "P<0.05 BMSC-Sna group, vs. BMSC-NC + NRG, BMSC + NRG, BMSC-NC, and BMSC groups. BMSC, bone marrow mesenchymal stem cells; Sna, Snail overexpression plasmid; NRG, neuregulin-1; NC, negative control; MMP-2, matrix metalloproteinase-2.
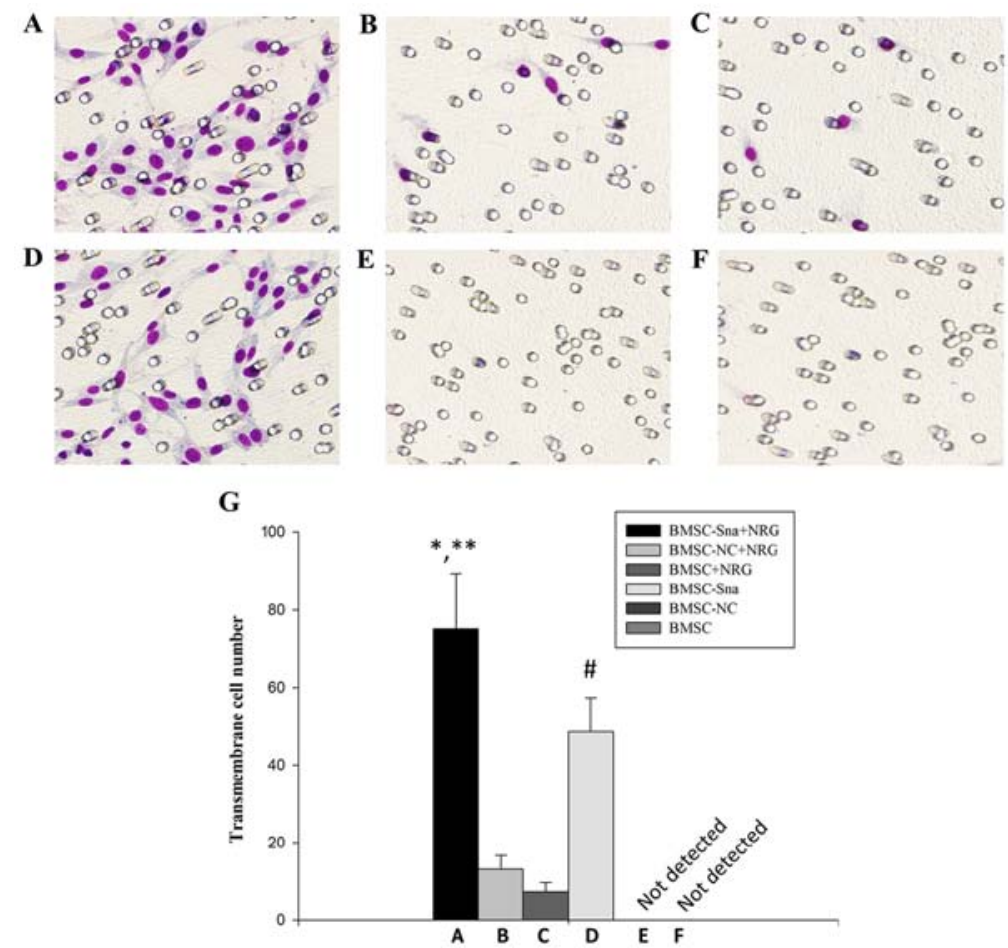

Figure 5. Cell migration of BMSCs in different groups. Images under an optical microscope (x100 magnification) of the (A) BMSC-Sna + NRG group, (B) BMSC-NC + NRG group, (C) BMSC + NRG group, (D) BMSC + Sna group, (E) BMSC-NC group and (F) BMSC group. (G) Numbers of transmembrane cells in groups A-F. Data are presented as the mean \pm standard deviation and $\mathrm{P}<0.05$ was considered statistically significant. " $\mathrm{P}<0.05 \mathrm{~A}, \mathrm{vs}$. B and $\mathrm{C}$; ${ }^{* * *} \mathrm{P}<0.05$ A, vs. D; ${ }^{\text {P }}<0.05$ D, vs. B and C. BMSC, bone marrow mesenchymal stem cells; Sna, Snail overexpression plasmid; NRG, neuregulin-1; NC, negative control.

which meant that BMSCs were temporarily modified with gene overexpression or silencing.

In the present study, it was found that exogenous NRG1 significantly promoted the expression of Snail in a concentration-dependent manner $<40 \mathrm{ng} / \mathrm{ml}$ with a peak at $48 \mathrm{~h}$. Further experiments were performed under this optimal condition. As overlapping mechanisms exist between stem cells and tumor cells (33-37), the transcription factor Snail, which is important in EMT, is involved in promoting the migration, invasiveness and metastatic potential of tumor cells (38-41). Therefore, BMSCs were modified with a Snail-overexpressed plasmid and changes in the expression of MMP-2 were detected with or without the addition of exogenous NRG1. The results indicated that NRG1 significantly promoted the expression of MMP-2 via upregulating the expression of Snail and contributing to BMSC migration in vitro. The synergistic effects of NRG1 on Snail can promote changes of the BMSC cytoskeleton, stimulate the expression of MMP-2 to degrade extracellular matrix, and enhance BMSC migration. The results of in vivo experiments in the present study further showed that BMSCs had a wide and uniform distribution area in the lesions of the SCI following treatment with BMSCs modified with Snail and NRG1.

Furthermore, the BBB scores indicated that the functional recovery of SCI was significantly improved following transplantation of the BMSCs modified with Snail and NRG1. The underlying mechanism of this promoting effect may be associated with the upregulation of MMP-2 and Snail following the addition of NRG1. The results suggested that NRG1 provided synergistic improvement of the positive effects of Snail on BMSC migration. BMSC transplantation 


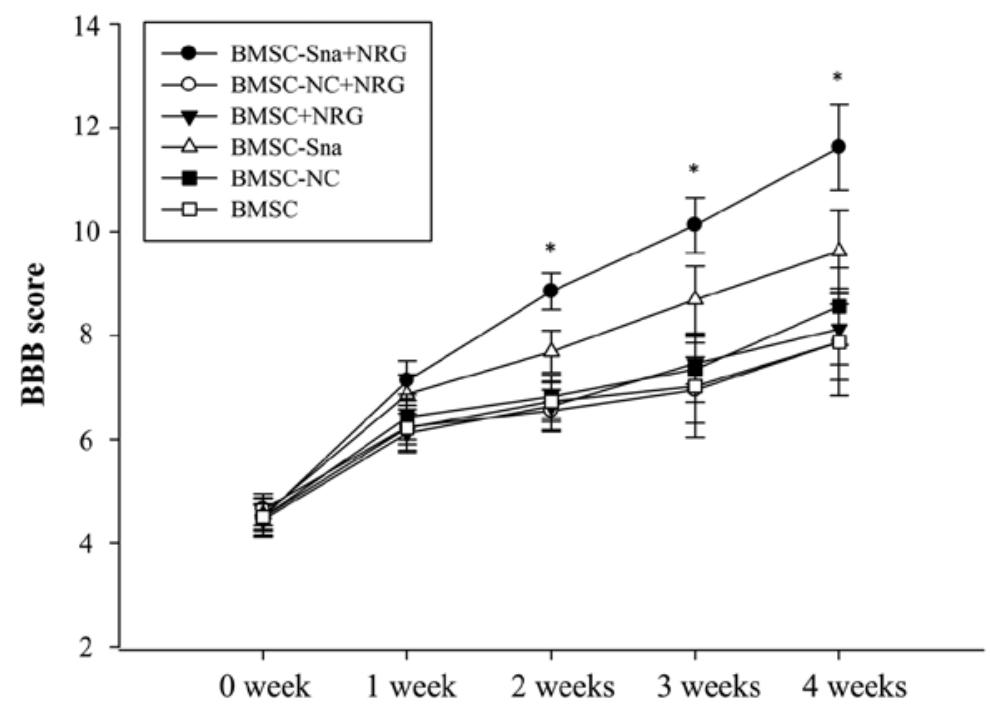

Figure 6. BBB scores at different time points. Data are presented as the mean \pm standard deviation and $\mathrm{P}<0.05$ was considered statistically significant. ${ }^{*} \mathrm{P}<0.05$ BMSC-Sna + NRG group, vs. all other groups. BBB, Basso, Beattie, and Bresnahan; BMSC, bone marrow mesenchymal stem cells; Sna, Snail overexpression plasmid; NRG, neuregulin-1; NC, negative control.
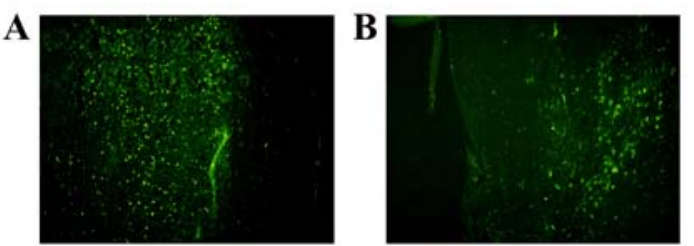

$\mathbf{D}$
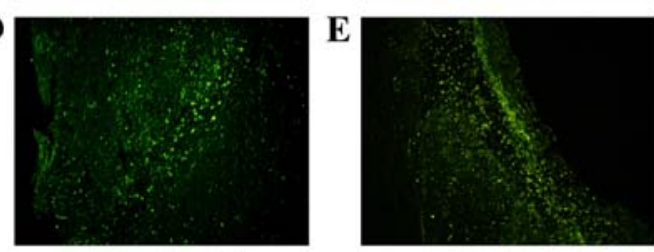

G

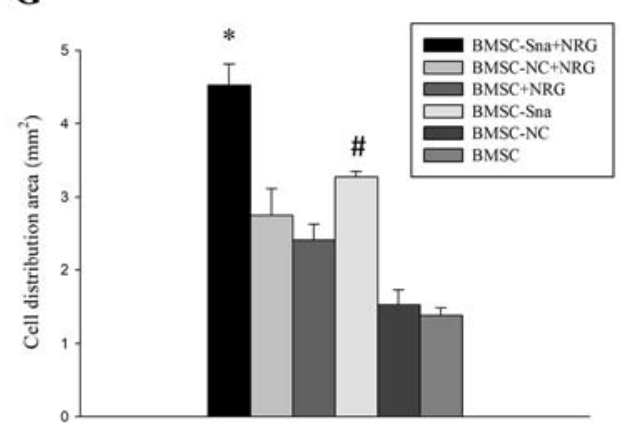

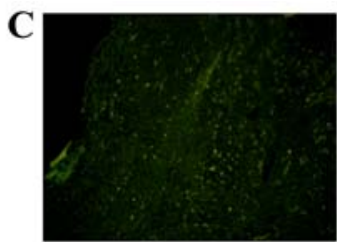

$\mathbf{F}$

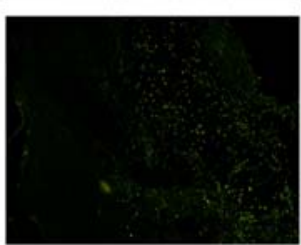

Figure 7. Morphological observation of BMSCs in different groups. Images of the spinal cord in the (A) BMSC-Sna + NRG group, (B) BMSC-NC + NRG group, (C) BMSC + NRG group, (D) BMSC + Sna group, (E) BMSC-NC group and (F) BMSC group under a fluorescent microscope (magnification, $\mathrm{x} 40$ ). (G) Distribution area of BMCSs. Data are presented as the mean \pm standard deviation and $\mathrm{P}<0.05$ was considered statistically significant. "P $<0.05$ BMSC-Sna + NRG group, vs. all other groups; ${ }^{~} \mathrm{P}<0.05$ BMSC-Sna group, vs. BMSC-NC and BMSC groups. BMSC, bone marrow mesenchymal stem cells; Sna, Snail overexpression plasmid; NRG, neuregulin-1; NC, negative control.

offers a novel and promising treatment for SCI and previous studies have confirmed that BMSC transplantation can improve neurological deficits effectively and efficiently. However, there were certain limitations, including the lack of more recent and advanced techniques, the insufficient number of experimental animal species and the lack of evaluation of the effect of BMSC migration following NRG1- or Snail-knockout.
In conclusion, NRG1 upregulated the expression of Snail in a concentration-dependent and promoted the expression of MMP-2 at the optimal concentration and time point; this enhanced the migration of rat BMSCs in vitro. In addition, NRG1 led to the BMSCs diffusing uniformly in the SCI location and showed good functional recovery following SCI. This suggests that NRG1 may be essential in the cell transplantation of modified BSMCs in treating SCI. 


\section{Acknowledgements}

Not applicable.

\section{Funding}

The present study was sponsored by National Natural Science Foundation of China (grant no. 81070971), who had no role in study design, data collection and analysis, decision to publish, or preparation of the manuscript.

\section{Availability of data and materials}

The datasets used and/or analyzed during the current study are available from the corresponding author on reasonable request.

\section{Authors' contributions}

$\mathrm{XY}, \mathrm{YC}$ and GT were involved in conception and design, collection and assembly of data, analysis and interpretation of data, statistical expertise, drafting of the manuscript, final approval of the manuscript, provision of study materials and administrative, technical or logistic support; analysis and interpretation of data, critical revision of the manuscript for important intellectual content. All authors contributed equally.

\section{Ethics approval and consent to participate}

This study was approved by the Ethics Committee of The First Affiliated Hospital of China Medical University (Shenyang, China). Participants provided written informed consent to participate in the study.

\section{Patient consent for publication}

Not applicable.

\section{Competing interests}

The authors declare that they have no competing interests.

\section{References}

1. Jain NB,Ayers GD,PetersonEN,Harris MB,Morse L, O'Connor KC and Garshick E: Traumatic spinal cord injury in the United States, 1993-2012. JAMA 313: 2236-2243, 2015.

2. Hofstetter CP, Schwarz EJ, Hess D, Widenfalk J, El Manira A, Prockop DJ and Olson L: Marrow stromal cells form guiding strands in the injured spinal cord and promote recovery. Proc Natl Acad Sci USA 99: 2199-2204, 2002.

3. Qu J and Zhang H: Roles of mesenchymal stem cells in spinal cord injury. Stem Cells Int 2017: 5251313, 2017.

4. Nakano N, Nakai Y, Seo TB, Homma T, Yamada Y, Ohta M, Suzuki Y, Nakatani T, Fukushima M, Hayashibe M and Ide C: Effects of bone marrow stromal cell transplantation through CSF on the subacute and chronic spinal cord injury in rats. PLoS One 8: e73494, 2013.

5. Miyahara Y, Nagaya N, Kataoka M, Yanagawa B, Tanaka K, Hao $\mathrm{H}$, Ishino $\mathrm{K}$, Ishida $\mathrm{H}$, Shimizu $\mathrm{T}$, Kangawa $\mathrm{K}$, et al: Monolayered mesenchymal stem cells repair scarred myocardium after myocardial infarction. Nat Med 12: 459-465, 2006.

6. Wright KT, El Masri W, Osman A, Chowdhury J and Johnson WE: Concise review: Bone marrow for the treatment of spinal cord injury: Mechanisms and clinical applications. Stem Cells 29: 169-178, 2011.
7. Mei L and Nave KA: Neuregulin-ERBB signaling in the nervous system and neuropsychiatric diseases. Neuron 83: 27-49, 2014.

8. Birchmeier C and Bennett DL: Neuregulin/ErbB signaling in developmental myelin formation and nerve repair. Curr Top Dev Biol 116: 45-64, 2016.

9. Lai D, Liu X, Forrai A, Michalicek J, Ahmed I, Garratt AN, Birchmeier C, Zhou M, Hartley L, Robb L, et al: Neuregulin 1 sustains the gene regulatory network in both trabecular and nontrabecular myocardium. Circ Res 107: 715-727, 2010.

10. Simmons LJ, Surles-Zeigler MC, Li Y, Ford GD, Newman GD and Ford BD: Regulation of inflammatory responses by neuregulin-1 in brain ischemia and microglial cells in vitro involves the NF-kappa B pathway. J Neuroinflammation 13: 237, 2016.

11. Ritch PS, Carroll SL and Sontheimer H: Neuregulin-1 enhances survival of human astrocytic glioma cells. Glia 51: 217-228, 2005.

12. Finigan JH, Faress JA, Wilkinson E, Mishra RS, Nethery DE, Wyler D, Shatat M, Ware LB, Matthay MA, Mason R, et al: Neuregulin-1-human epidermal receptor-2 signaling is a central regulator of pulmonary epithelial permeability and acute lung injury. J Biol Chem 286: 10660-10670, 2011.

13. Brea MS, Díaz RG, Escudero DS, Caldiz CI, Portiansky EL, Morgan PE and Pérez NG: Epidermal growth factor receptor silencing blunts the slow force response to myocardial stretch. J Am Heart Assoc 5: e004017, 2016.

14. Vermeulen Z, Hervent AS, Dugaucquier L, Vandekerckhove L, Rombouts M, Beyens M, Schrijvers DM, De Meyer GRY, Maudsley S, De Keulenaer GW and Segers VFM: Inhibitory actions of the NRG-1/ErbB4 pathway in macrophages during tissue fibrosis in the heart, skin, and lung. Am J Physiol Heart Circ Physiol 313: H934-H945, 2017.

15. Woo RS, Lee JH, Kim HS, Baek CH, Song DY, Suh YH and Baik TK: Neuregulin-1 protects against neurotoxicities induced by swedish amyloid precursor protein via the ErbB4 receptor. Neuroscience 202: 413-423, 2012.

16. Miyagawa S, Katsu Y, Watanabe H and Iguchi T: Estrogenindependent activation of erbBs signaling and estrogen receptor alpha in the mouse vagina exposed neonatally to diethylstilbestrol. Oncogene 23: 340-349, 2004.

17. Motoyama AB, Hynes NE and Lane HA: The efficacy of ErbB receptor-targeted anticancer therapeutics is influenced by the availability of epidermal growth factor-related peptides. Cancer Res 62: 3151-3158, 2002.

18. Alvarado D, Ligon GF, Lillquist JS, Seibel SB, Wallweber G, Neumeister VM, Rimm DL, McMahon G and LaVallee TM: ErbB activation signatures as potential biomarkers for anti-ErbB3 treatment in HNSCC. PLoS One 12: e0181356, 2017.

19. Wingens $M$, Walma $T$, van Ingen $H$, Stortelers $C$, van Leeuwen JE, van Zoelen EJ and Vuister GW: Structural analysis of an epidermal growth factor/transforming growth factor-alpha chimera with unique ErbB binding specificity. J Biol Chem 278: 39114-39123, 2003.

20. Vullhorst D, Ahmad T, Karavanova I, Keating C and Buonanno A: Structural similarities between neuregulin 1-3 isoforms determine their subcellular distribution and signaling mode in central neurons. J Neurosci 37: 5232-5249, 2017.

21. Greenburg G and Hay ED: Epithelia suspended in collagen gels can lose polarity and express characteristics of migrating mesenchymal cells. J Cell Biol 95: 333-339, 1982.

22. Wang Y, Shi J, Chai K, Ying X and Zhou BP: The role of snail in EMT and tumorigenesis. Curr Cancer Drug Targets 13: 963-972, 2013.

23. Xia J, Luo M, Ni N, Chen J, Hu Y, Deng Y, Ji J, Zhou J, Fan X and Gu P: Bone marrow mesenchymal stem cells stimulate proliferation and neuronal differentiation of retinal progenitor cells. PLoS One 8: e76157, 2013.

24. Hu JZ, Wu TD, Zhang T, Zhao YF, Pang J and Lu HB: Three-dimensional alteration of microvasculature in a rat model of traumatic spinal cord injury. J Neurosci Methods 204: $150-158,2012$

25. Basso DM, Beattie MS and Bresnahan JC: A sensitive and reliable locomotor rating scale for open field resting in rats. J Neurotrauma 12: 1-21, 1995.

26. Svkova E, Jendelova P, Urdzikova L, Lesný P and Hejcl A: Bone marrow stem cells and polymer hydrogels-two strategied for spinal cord injury repair. Cell Mol Neurobiol 26: 1113-1129, 2006.

27. Sykova E, Homola A, Mazanec R, Lachmann H, Konrádová SL, Kobylka P, Pádr R, Neuwirth J, Komrska V, Vávra V, et al: Autologous bone marrow transplantation in patients with subacute and chronic spinal cord injury. Cell Transplant 15: 675-687, 2006. 
28. Hill WD, Hess DC, Martin-Studdard A, Carothers JJ, Zheng J, Hale D, Maeda M, Fagan SC, Carroll JE and Conway SJ: SDF-1 (CXCL12) is upregulated in the ischemic penumbra following stroke: Association with bone marrow cell homing to injury. J Neuropathol Exp Neurol 63: 84-96, 2004.

29. Wang L, Li Y, Chen X, Chen J, Gautam SC, Xu Y and Chopp M: MCP-1, MIP-1, IL-8 and ischemic cerebral tissue enhance human bone marrow stromal cell migration in interface culture. Hematology 7: 113-117, 2002.

30. Lu D, Mahmood A, Wang L, Li Y, Lu M and Chopp M: Adult bone marrow stromal cells administered intravenously to rats after traumatic brain injury migrate into brain and improve neurological outcome. Neuroreport 12: 559-563, 2001.

31. Serakinci N, Guldberg P, Burns JS, Abdallah B, Schrødder H, Jensen T and Kassem M: Adult human mesenchymal stem cell as a target for neoplastic transformation. Oncogene 23: 5095-5098, 2004.

32. Rubio D, Garcia-Castro J, Martin MC, de la Fuente R, Cigudosa JC, Lloyd AC and Bernad A: Spontaneous human adult stem cell transformation. Cancer Res 65: 3035-3039, 2005.

33. Reya T, Morrison SJ, Clarke MF and Weissman IL: Stem cells, cancer, and cancer stem cells. Nature 414: 105-111, 2001.

34. Burkert J, Wright NA and Alison MR: Stem cells and cancer: An intimate relationship. J Pathol 209: 287-297, 2006.

35. Al-Hajj M, Becker MW, Wicha M, Weissman I and Clarke MF Therapeutic implications of cancer stem cells. Curr Opin Genet Dev 14: 43-47, 2004.

36. Nakagawara $\mathrm{A}$ and Ohira $\mathrm{M}$ : Comprehensive genomics linking between neural development and cancer: Neuroblastoma as a model. Cancer Lett 204: 213-224, 2004.
37. Zha YH, He HF, Mei YW, Yin T and Mao L: Zinc-finger transcription factor Snail accelerates survival, migration and expression of matrix metalloproteinase-2 in human bone mesenchymal stem cells. Cell Biol Int 31: 1089-1096, 2007.

38. Ikernouchi J, Matsuda M, Furuse M and Tsukita S: Regulation of tight junctions during the epithelium-mesenchyme transition: Direct repression of the gene expression of claudins/occluding by snail. J Cell Sci 116: 1959-1967, 2003.

39. Yang AD, Camp ER, Fan F, Shen L, Gray MJ, Liu W, Somcio R, Bauer TW, Wu Y, Hicklin DJ and Ellis LM: Vascular endothelial growth factor receptor-1 activation mediates epithelial to mesenchymal transition in human pancreatic carcinoma cells. Cancer Res 66: 46-51,2006.

40. Gotzmann J, Fischer AN, Zojer M, Mikula M, Proell V, Huber H, Jechlinger M, Waerner T, Weith A, Beug $\mathrm{H}$ and Mikulits W: A crucial function of PDGF in TGF-beta-mediated cancer progression of hepatocyers. Oncogene 25: 3170-3185, 2006.

41. Cheng L, Zha Z, Lang B, Liu J and Yao X: Heregulin-beta promotes metastasis of breast cancer cell line SKBR3 through upregulation of Snail and induction of epithelial-mesenchymal transition. Cancer Lett 280: 50-60, 2009.

(1) (9) This work is licensed under a Creative Commons Attribution-NonCommercial-NoDerivatives 4.0 International (CC BY-NC-ND 4.0) License. 